\section{Mierarchy in organizations}

Por Arnold S. Tannenbaum et alli., San Francisco Jossey Bass Publishers, 1974, IX-XVII, 248p. US\$12.50.

O livro é resultado de um esforco intelectual multinacional: o autor, Anold Tannenbaum, que encabeça a lista, \& norte-americano, e seus colaboradores sáo todos eles de diferentes paises. Mino Vlanello e da Italia, Bodan Kavcic, da lugoslávla, Menachem Rosner, de Israel e Georg Wiesner, da Austria.

O livro tenta atingir dois objetivos atuais e relevantes para o estudo de organizaçoes: 1. a analise comparativa, uma vez que inclui $\mathbf{4 5}$ fabricas, em cinco indüstrias diversas (plásticos, fundiçăo, alimenticia, metalúrgica e móveis); 2 . a verificaçăo de diferenças motivadas por contextos culturals diversos, uma vez que as fabricas se localizam em cinco sistemas culturais, o norte-americano, o italiano, $O$ austriaco, 0 iugoslavo $\bullet 0$ KIbbutz. A característica organizacional escolhida para a analise comparada e intercultural e a hierarquia. Organizaços formais possuem a caracteristica da hierarquizaçăo, que corresponde năo apenas a necessidades geradas pela estrutura de tarefas, mas também implica em distribuicáo desigual de poder, dinheiro, prestiglo, status e simbolos.

A escolha dos cinco sistemas culturais mencionados objetiva comparar hierarquia organizacional em sistemas capitalistas como a Itália, os Estados Unidos e a Áustria e em sistemas socialistas como a lugoslavia e o Kibbutz. Embora haja diferenças entre os tres sistemas capitalistas, pois 0 capitalismo assume caracteristicas diversas em cada um dos paises escolhidos - e também e verdade que a lugoslávia $e$ Kibbutz representam socialismos diferentes - permanecem os propósitos fundamentais de cada sistema. O capitalista é diferenciado, com os meios de produçác concentrados em máos de poucos membros da sociedade, com enfase na competiçăo. Na exaltaçăo individual $e$, de outro, o socialismo, com a propriedade individual quase inteiramente abolida, com objetivos de igualdade e cooperaçăo entre os membros da sociedade e buscando uma distribuiçào Igualitária dos resultados da atividade economica. Poder-se-ia dizer que enquanto a hierarquia e natural a um sistema, ela seria, quando multo, tolerada como resultado da divisao de tarefas no outro, mas cujos efeitos deverăo ser minimizados, cumprindo encontrar os antidotos que impeçam a perpetuaçăo da desigualdade entre os membros da sociedade.

Independente dos propósitos que socialismo e capitalismo formulam, as organizaçoes, em todos os sistemas que compóem o capitalismo, de um lado, e o socialismo, do outro, manifestam caracteristicas hierarquicas, o que nåo delxa de ser motivo de perplexidade.

Após um capitulo inicial onde hierarquia organizacional e definida $a$ operacionalizada, 0 segundo nos fala das diferenças existentes entre os cinco sistemas económicos, sendo os capitulos tres, quatro cinco dedicados respectivamente a controle e processo decisório, ênfase na hierarquia e gradientes de ajustamento e reaçá. As fábricas do sistema socialista (Kibbutz e lugoslávia) surgem como mais participativas do que as capitalistas, embora as lugoslavas sejam. bem menos participativas do que as do Kibbutz, o que poderla ser explicado pelo passado tradicional e feudal da sociedade iugoslava que năo fol experlmentado pelo sistema Kibbutz. Do lado capitalista maior participaçăo se encontra no sistema norte-americano e a menor no italiano, onde o autoritarismo e maior. Tal fato explica-se pelo caráter familiar do capitalismo italiano, que năo dispōe, abaixo dos proprietários, a capa de "managers" profissionalizados, tăo característica do empresarialismo dos Estados Unidos.

o capitulo quarto analisa a ênfase dada à hlerarquia a partir da percepçáo que dela possuem os membros da organização. É o capitulo mais longo do livro e a percepçăo e medida atraves das variavels: a) atitude com relaçăo a promoçós; b) percepçáo de requisitos e exigencias para o avanco; c) autoridade e influência; d) oportunidades do cargo; e) qualidades físicas do emprego; f) salario; g) caracteristicas demograficas; h) hierarquia. O interesse por promoços e acesso e menor nas plantas iugoslavas $\theta$ de Kibbutz do que nas capitalistas, especialmente norteamericanas, onde prestigio, status e salários são mais variáveis, dependendo do nível hierárquico do individuo. Todavia, a qualidade física do trabalho conduz a gradientes igualmente inclinados em plantas dos cinco sistemas, inclusive das lugoslavas, que săo as mais achatadas (flat), o que pode ser explicado por razós exclusivamente tecnologicas.

No que diz respeito educação formal dos membros, as fábricas lugoslavas e italianas indicam maior inclinaçăo, enquanto as do Klbbutz a menor. As variáveis comuns aos cinco sistemas săo autoridade e ln- 
fluência, que aumentam segundo o grau de hierarquizaçào. As fabricas do sistema Kibbutz sâo as que possuem 0 gradiente menos inclinado e as italianas o mais indicado, porem săo variaçces em torno de inclinaçoes bastante grandes. Portanto, os dois sistemas em comparação (socialismo capitalismo) manifestam esta caracteristica em comum de que autoridade e influência são desigualmente distribuidas, apesar dos esforcos que os socialistas envidam no sentido de minorar as discrepancias hierárquicas.

O capitulo quinto trata das formas pelas quais os indivlduos se adaptam ou se ajustam a realidade hierárquica das fabricas, o que operacionalizado pela medição de atitudes com relaçăo a satisfaçăo, motivaçăo, adaptaçăo, percepçoes e ideais. A constataçăo mais universal $B$ a de que nivel hierárquico e satisfaçăo, e envolvimento organizacional estáo positivamente correlacionados nos cinco sistemas. Isto evidencia a universalidade do principio da hierarquia. A educaçăo tem grande importância como fator que modela a interface individuoorganização. Embora educaçào diminua alienaçăo, ela contribui ao aumento de insatisfaçăo e da frustração. As pessoas mais educadas são as que mais se frustraça e ficarăo insatisfeitas com a maioria das tarefas existentes numa organização. Outra caracteristica comum aos cinco sistemas fol a verificaçăo de que nào existe relaçăo entre salário $\theta$ nivel de satisfaçăo, o que comprovaria a tese do salário como fator higienico.

O sexto capítulo tenta sintetizar as caracteristicas da organização hierárquica com base nos dados apresentados ao longo do livro e especialmente do capitulo cinco. Em termos de percepçóes e ideals que os membros possuem, a discrepancia e bastante grande, dependendo do nivel hierarquico. Os que se encontram nos niveis mais baixos nao so percebem a organização diferentemente daqueles que se encontram em posiçóes mais elevadas, mas tambem manifestam major interesse de que a organizaçăo sofresse modificaçoes.

Finalmente, o capitulo setimo alinha conclusoes em torno do tenomeno hierárquico nos sistemas socialista capitalista. Cumpre ressaltar a universalldade $\theta$ a inevitabilidade da hierarquia, bem como a constataça de que hierarquia comporta graus, ou seja, as organizaçoes săo mais ou menos hierárquicas. Em ambos os sistemas, a hierarquia fundamenta-se em necessidades de divisăo de tarefas, mas acaba por gerar niveis diversos de envolvimento elou alienaçăo entre os membros da organizaçào.

Todas estas caracteristicas independem de 0 sistema ser capitalista ou socialista. É por outro lado verdadeiro que o marxismo legitima a hierarquia tāo somente em funçăo de necessidades de coordenaça $e$ controle de tarefas, enquanto o capitalismo, especialmente no caso norte-americano, associa niveis hierárquicos mais altos com sucesso, perseverança, trabalho arduo e competencia. Todas estas caracteristicas foram objeto de culdadoso esforço teórico consubstanciada na obra de D. McClelland em torno do "achievement" (motivation). A consequencia a de que, num sistema, os desdobramentos da hierarquia sob forma de prestigio, status e rendas mais elevadas, tendem a ser minimizados. No outro, estes desdobramentos săo sistematicamente realçados $\theta$ utilizados como allciadores para motivar individuos à dedicaça e ao esforço em beneficio dos objetlvos or ganizacionais.

Porém, a comparação das principais caracteristicas da burocracia nos dois modelos extremos, os Estados Unidos e - Kibbutz, indicam diferenças fundamentais no que diz respeito a decisoes, gradientes de autoridade e recompensa, relaçoes entre superiores e subordinados, tipos de ajustamento ou adaptaça a organizaçăo e a legitimidado do sistema administrativo. $0 \mathrm{KIb}$ butz tende mais a manifestaçăo dos atributos de um sistema IV de Rensis Likert, enquanto os Estados Unidos tenderiam mais asquerda do contínuo proposto por Likert.

Permanece, todavia, o fato de que envolvimento $\theta$ participaçăo, representados por baixos niveis de alienaçá, stao elevados no sistema dos Estados Unidos, alcançados através de motivaçoes tradicionais, e relativamente mais baixos na lugoslavia socialista, a despeito da enfase em autogesta e particlpaça.

- trabalho empreendido pelos cinco pesquisadores, encabeçados por Arnold Tannenbaum, é um esforço meritório. As limitaços do trabalho, que retiram dele multo das possibilidades de generalizaçăo, săo inteligiveis e ate certo ponto inevitaveis. $O$ estudioso metodologicamente exigente decepciona-se com a inadequaça do estudo para satisfazer as exigencias de uma analise que possa ser considerada comparativa. $\mathrm{Na}$ verdade, estamos dlante de um "case study" sofisticado e de tipo "cross cultural". A grande variável ausente é o tamanho, da qual breve mençáo é feita no final (p. 224), mas que, se introduzida, contribuiria bastante para esclarecer vários pontos. Tanto o trabalho de Peter Blau e associados, como o do Grupo de Aston, exploraram as consequenclas e cognatos do tamanho a ponto de tornar imprudente analisar organizaços sem levar em consideraça suas conclusoes. Os autores de Hierarchy in organizations, da Jossey Bass Publishers, permanecem, contudo, sllenciosos a respeito, em toda a extensấo do seu trabalho.

O livro é contribuiçăo importante à concepção de que organizaçóes formais năo constituem necessariamente um capitulo no estudo funcionalista da organizaçăo social, mas 
pode ser o instrumento prlvileglado no entendimento do que ocorre na socledade global - nos conflitos $\theta$ tensdes explicitos ou subjacentes om qualquer sociedade. Comparando organizaçoes fabris em sociedades capitalistas $\theta$ socialistas, A. Tannenbaum e seus associados nos delxam vislumbrar, atraves do crivo empirico, muitas semelhanças mais desconcertantes nos dois sistemas do que ldeologicamente se deveria esperar.

Carlos Osmar Bertero

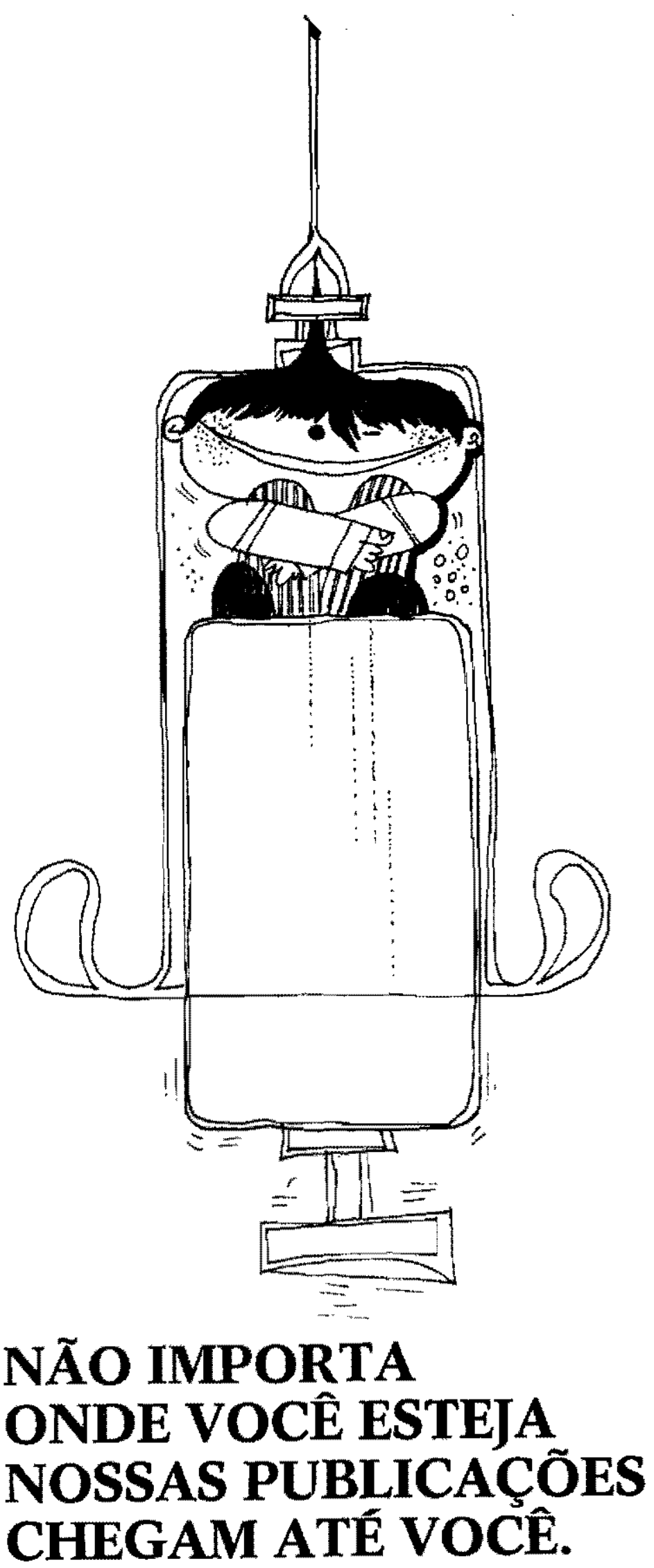

Basta pedir pelo Reembolso Postal Editora da FGV - Praia de Botafogo, 190 CP 9052 - ZC-02 - Rio de Janeiro 